\title{
Application of diverse FACTS in AGC of multi-area interconnected energy systems
}

Gulshan Sharma, Kabulo Loji, Musasa Kabeya

Department of Electrical Power Engineering, Durban University of Technology, South Africa

\begin{tabular}{|c|c|}
\hline Article Info & ABSTRACT \\
\hline Article historys: & \multirow{11}{*}{$\begin{array}{l}\text { This article presents the simple and effective control design for active power } \\
\text { regulation of modern energy delivery system. As an energy delivery system } \\
\text { experiences the demand changes as per the demand of the modern energy users } \\
\text { due to which the system frequency is highly troubled and fluctuating. } \\
\text { To balance such demand changes and to stable the system occurrence } \\
\text { fluctuations, the thyristor control phase shifter (TCPS) in synchronisation with } \\
\text { super conducting magnetic energy storage (SMES) or TCPS in coordination } \\
\text { with capacitive energy storage (CES) based model predictive control (MPC) } \\
\text { technique are proposed. SMES-SMES and CES-CES configurations are also } \\
\text { tested for energy delivery system. The effectiveness of the proposed system } \\
\text { regulator design is guaranteed by analyzing the transient system performance } \\
\text { under varying load pattern, sinusoidal load change and for system non- } \\
\text { linearities. A comparative performance analysis between TCPS-SMES, } \\
\text { TCPS-CES, SMES-SMES and CES-CES based MPC of energy system are } \\
\text { tested and presented. }\end{array}$} \\
\hline Received Feb 22, 2019 & \\
\hline & \\
\hline Accepted Apr 18, 2019 & \\
\hline Keywords: & \\
\hline Automatic generation control & \\
\hline Capacitive energy storage & \\
\hline Model predictive control & \\
\hline Super conducting magnetic & \\
\hline energy storage & \\
\hline Thyristor control phase shifter & \\
\hline
\end{tabular}

Copyright (C) 2019 Institute of Advanced Engineering and Science. All rights reserved.

\section{Corresponding Author:}

Gulshan Sharma,

Department of Electrical Power Engineering,

Durban University of Technology,

Steve Biko Campus, 70 Steve Biko Road, Durban 4001, South Africa.

Email: gulshanS1@dut.ac.za

\section{INTRODUCTION}

An important aspect of electrical power delivery system is the automatic generation control (AGC) which manages to supply enough and cheap electricity for modern power consumers. An AGC role is to maintain the system generations with the load demand in addition to maintaining the exchange of power between the control areas within its fixed limits [1-7]. Due to increase in modern energy system size, the insufficient control strategies may deteriorate the system frequency due to which the system oscillations might transmit into a wider area leading to system blackout. Further, Because of the operational system constraints associated with thermal power plants, the solutions proposed to till date for AGC have not been implemented in practice. The rationale behind this is the required storage energy capacity is not available other than the generator rotor inertia [8]. In addition to the kinetic energy of generator rotors, fast acting energy storage devices provide storage capacity that can share the systems sudden changes in power demand and effectively improve the system performance. The Battery Energy Storage System (BESS) to improve West Berlin Electric Power Supply's AGC performance was reported in [9]. However, problems such as low discharge rates, repair requirements and increased power flow reversal time have resulted in the development of superconducting magnetic energy storage (SMES) as an efficient frequency stabilizer.

SMES can control active and reactive power in electrical energy systems and is an effective stabilizer for improving frequency oscillations in interconnected systems [10]. However, in the area of its installation, the encouraging results of SMES are observed and have almost no or very little contribution to frequency control or AGC performance achievement in other control areas. Further, it is also not suggested for economic 
reasons that SMES units should be installed in each control area. The thyristor control phase shifter (TCPS) is another much cheaper FACTS device and tends to regulate the power exchange between the control areas in a much more efficient way [11].

The Capacitive energy storage (CES) is also a FACTS device that is much cheaper in comparison to other FACTS - based controllers and can improve frequency oscillations in a modern energy delivery system [12-14]. In [12], the authors have investigated the advancement of system performance through CES and TCPS over that achieved with the other FACTS based controllers for interconnected thermal-hydro and hydro-diesel system.

On the other hand, the model predictive control (MPC) proves to be an effective control technique for various applications in different control industries. MPC action is quite fast in comparison to other control actions, robust performance for variation in system parameters as well as for load demand. The MPC design is simple yet effective. Given a system model, an objective function is to formulate to meet the control target requirements. In addition, the MPC is well suited for various physical installations and enables the unified approach [15-16]. From the above discussion it is observed that very few researches work to study the impact of various FACTS based frequency stabilizers were available in the AGC literature. Further it is also noted that MPC based technique need to be investigated for AGC studies and hence following objectives are formulated for the present research work which are as follows;

- Design the different combination of FACTS based frequency stabilizers for AGC of an interconnected energy delivery system. The various combinations such as TCPS-SMES, TCPS-CES, SMES-SMES and CES-CES based frequency stabilizers are investigated in an interconnected energy system.

- A TCPS - SMES, TCPS - CES, SMES - SMES and CES - CES analysis is provided on the basis of MPC technique to demonstrate the superiority and efficacy of one combination over the others for standard load demand of 1 per cent in one control area.

- An investigation was also performed to examine the effect of random load disturbance \&, sinusoidal load change in coordination control of TCPS-SMES, TCPS-CES, SMES-SMES and CES-CES based on MPC technique.

- The system performance is also tested in view of governor dead band and generation rate constraint (GRC) non-linearity and the achieved results are taken into the consideration.

The rest of the article is arranged accordingly. The system model is presented in Section 2, following the state-variable model, TCPS, SMES and CES mathematical model for AGC. The modeling of the dead band and the GRC is also given in Section 2. Section 3 shows the MPC design \& Section 4 provide the detailed discussion on simulation results with conclusion in Section 5 finally.

\section{THE SYSTEM MODEL}

The control areas comprising the same plants with same capacity having the thermal reheater turbines connected by means of EHVAC link is used for the present research work. Figure 1 shows the detailed system transfer function model.

\subsection{Model in State Variable Form}

The dynamic model of the system is as follows:

$$
\begin{aligned}
& \frac{d}{d t}[x(t)]=A x(t)+B u(t)+E d(t), \\
& y(t)=C x(t),
\end{aligned}
$$

The structures of the vectors of state, control and disturbance:

\section{State, Control and Disturbance Vectors}

$$
\begin{aligned}
& {\left[X_{1}\right]^{T}=\left[\Delta F_{1} \Delta F_{2} \Delta P_{\text {tiel } 2} \int A C E_{1} d t \int A C E_{2} d t \Delta P_{g 1} \Delta P_{g 2} \Delta P_{R 1} \Delta P_{R 2} \Delta X_{g 1} \Delta X_{g 2}\right],} \\
& {\left[U_{1}\right]=\left[\Delta P_{c 1} \Delta P_{c 2}\right]^{T} \text {, }} \\
& {\left[P_{d 1}\right]=\left[\Delta P_{d 1} \Delta P_{d 2}\right]^{T} \text {. }}
\end{aligned}
$$

Indo. J. Elec. Eng. \& Inf, Vol.7, No. 2, June 2019: 241 - 254 

in Section 2:

The state, control and disturbance arrays are provided in accordance with the model details as provided

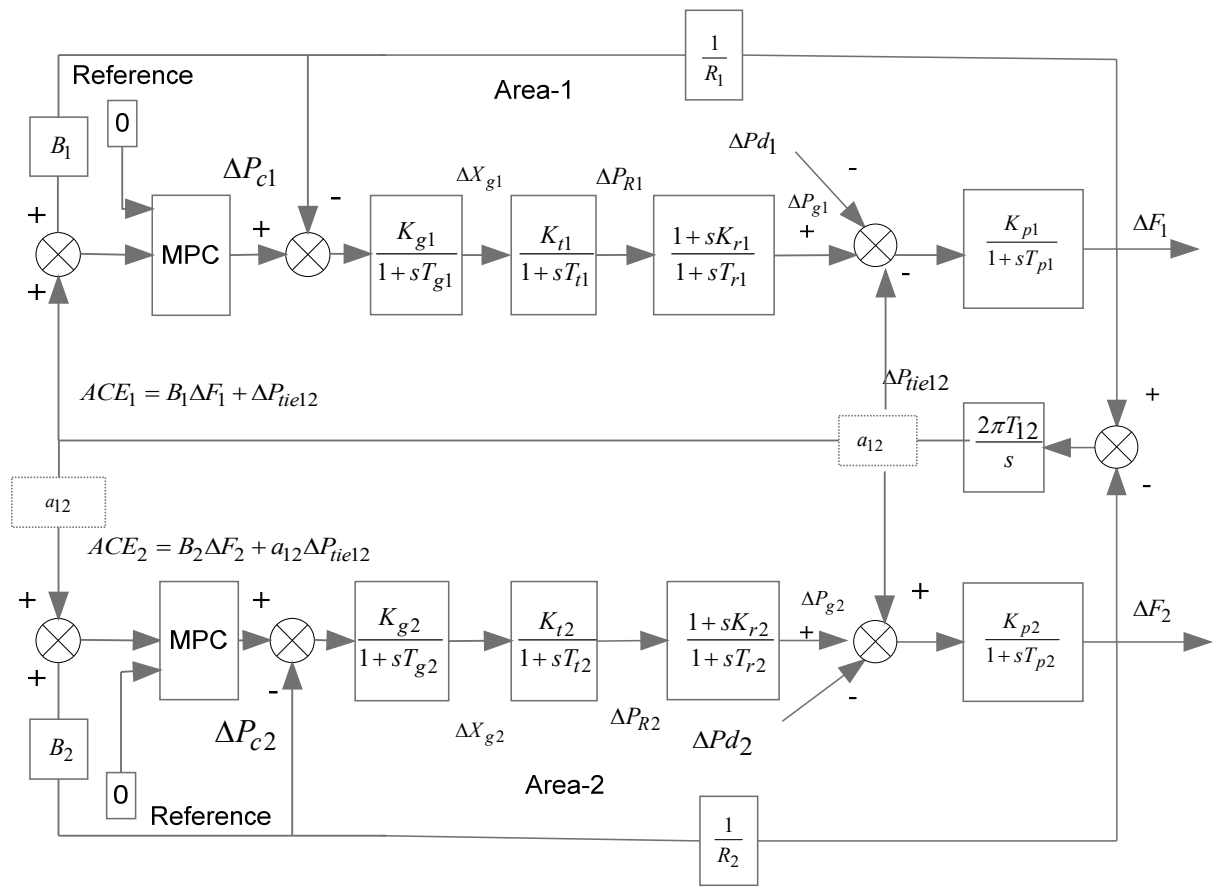

Figure 1.The considered system model

State matrix $A$ :

\begin{tabular}{|c|c|c|c|c|c|c|c|c|c|c|}
\hline$\frac{-1}{T_{P 1}}$ & $\frac{K_{p 1}}{T_{p 1}}$ & 0 & 0 & 0 & 0 & 0 & 0 & $\frac{-K_{p 2}}{T_{p 2}}$ & 0 & 0 \\
\hline 0 & $\frac{-1}{T_{r 1}}$ & $\frac{1}{T_{r 1}}-\frac{K_{r 1}}{T_{t 1}}$ & $\frac{K_{t 1} K_{r 1}}{T_{t 1}}$ & 0 & 0 & 0 & 0 & 0 & 0 & 0 \\
\hline 0 & 0 & $\frac{-1}{T_{t 1}}$ & $\frac{K_{t 1}}{T_{t 1}}$ & 0 & 0 & 0 & 0 & 0 & 0 & 0 \\
\hline$\frac{-K_{g 1}}{R_{1} T_{g 1}}$ & 0 & 0 & $\frac{-1}{T_{g 1}}$ & 0 & 0 & 0 & 0 & 0 & 0 & 0 \\
\hline 0 & 0 & 0 & 0 & $\frac{-1}{T_{p 2}}$ & $\frac{K_{p 2}}{T_{p 2}}$ & 0 & 0 & $\frac{-a_{12} K_{p 2}}{T_{p 2}}$ & 0 & 0 \\
\hline 0 & 0 & 0 & 0 & 0 & $\frac{-1}{T_{r 2}}$ & $\frac{1}{T_{r 2}}-\frac{K_{r 2}}{T_{t 2}}$ & $\frac{K_{t 2} K_{r 2}}{T_{t 2}}$ & 0 & 0 & 0 \\
\hline 0 & 0 & 0 & 0 & 0 & 0 & $\frac{-1}{T_{t 2}}$ & $\frac{K_{t 2}}{T_{t 2}}$ & 0 & 0 & 0 \\
\hline 0 & 0 & 0 & 0 & $\frac{-K_{g 2}}{R_{2} T_{g 2}}$ & 0 & 0 & $\frac{-1}{T_{g 2}}$ & 0 & 0 & 0 \\
\hline $2 \pi T_{12}$ & 0 & 0 & 0 & $-2 \pi T_{12}$ & 0 & 0 & 0 & 1 & 0 & 0 \\
\hline$B_{1}$ & 0 & 0 & 0 & 0 & 0 & 0 & 0 & 1 & 0 & 0 \\
\hline 0 & 0 & 0 & 0 & $B_{2}$ & 0 & 0 & 0 & $a_{12}$ & 0 & 0 \\
\hline
\end{tabular}


Control matrix B:

$$
[B]^{T}=\left[\begin{array}{ccccccccccc}
0 & 0 & 0 & \frac{K_{g 1}}{T_{g 1}} & 0 & 0 & 0 & 0 & 0 & 0 & 0 \\
0 & 0 & 0 & 0 & \frac{K_{g 2}}{T_{g 2}} & 0 & 0 & 0 & 0 & 0 & 0
\end{array}\right] .
$$

Disturbance matrix E:

$$
[E]^{T}=\left[\begin{array}{ccccccccccc}
\frac{-1}{M_{1}} & 0 & 0 & 0 & 0 & 0 & 0 & 0 & 0 & 0 & 0 \\
0 & 0 & 0 & 0 & \frac{-1}{M_{2}} & 0 & 0 & 0 & 0 & 0 & 0
\end{array}\right] .
$$

\subsection{Model of TCPS for AGC}

Figure 2 shows the scheme of an interconnected thermal-thermal two area system with TCPS close to area 1 in series with a tie-line. The TCPS model can be entered accordingly [11].

The small increased power over the tie-line from one control area to another can be modelled as:

$$
\Delta P_{t i e 12}^{0}(s)=\frac{T_{12}}{s}\left[\Delta \omega_{1}(s)-\Delta \omega_{2}(s)\right]
$$
be written as:

Due to TCPS close to area-1 in series with tie-line, the flowing of current from area-1 to area- 2 can

$$
\begin{aligned}
& i_{12}=\frac{\left|V_{1}\right| \angle\left(\delta_{1}+\varphi\right)-\left|V_{2}\right| \angle\left(\delta_{2}\right)}{J X_{12}} \\
& P_{t i e 12}-j Q_{t i e 12}=V_{1}^{*} i_{12}=\left|V_{1}\right| \angle-\left(\delta_{1}+\varphi\right)\left[\frac{\left|V_{1}\right| \angle\left(\delta_{1}+\varphi\right)-\left|V_{2}\right| \angle\left(\delta_{2}\right)}{j X_{12}}\right] \\
& P_{\text {tie12 }}-j Q_{t i e 12}=\frac{\left|V_{1}\right|\left|V_{2}\right|}{X_{12}} \sin \left(\delta_{1}-\delta_{2}+\varphi\right)-j \frac{\left[\left|V_{1}\right|^{2}-\left|V_{1}\right|\left|V_{2}\right| \cos \left(\delta_{1}-\delta_{2}+\varphi\right)\right]}{X_{12}}
\end{aligned}
$$

Speperate the real and imaginary parts of above equation and considering the real part only, we get

$$
P_{\text {tie } 12}=\frac{\left|V_{1}\right|\left|V_{2}\right|}{X_{12}} \sin \left(\delta_{1}-\delta_{2}+\varphi\right)
$$

In (7), perturbing $\delta_{1}, \delta_{2}$ and ${ }^{\varphi}$ from their nominal value $\delta_{1}^{O}, \delta_{2}^{O}$ and $\varphi^{O}$ yields:

$$
\Delta P_{t i e 12}=\frac{\left|V_{1}\right|\left|V_{2}\right|}{X_{12}} \cos \left(\delta_{1}^{o}-\delta_{2}^{o}+\varphi^{o}\right) \sin \left(\Delta \delta_{1}-\Delta \delta_{2}+\Delta \varphi\right)
$$

$\left(\Delta \delta_{1}-\Delta \delta_{2}+\Delta \varphi\right)$ is very small, hence for a small change in real power load, the variation of bus voltage angles and variation of TCPS phase angle are very small. Hence, we can write $\sin \left(\Delta \delta_{1}-\Delta \delta_{2}+\Delta \varphi\right) \approx\left(\Delta \delta_{1}-\Delta \delta_{2}+\Delta \varphi\right)$ Therefore,

$$
\Delta P_{t i e 12}=\frac{\left|V_{1}\right|\left|V_{2}\right|}{X_{12}} \cos \left(\delta_{1}^{o}-\delta_{2}^{o}+\varphi^{o}\right)\left(\Delta \delta_{1}-\Delta \delta_{2}+\Delta \varphi\right)
$$


Let $T_{12}=\frac{\left|V_{1}\right|\left|V_{2}\right|}{X_{12}} \cos \left(\delta_{1}^{o}-\delta_{2}^{o}+\varphi^{o}\right)$

Therefore, (9) reduces to

$$
\begin{aligned}
& \Delta P_{\text {tiel2 }}=T_{12}\left(\Delta \delta_{1}-\Delta \delta_{2}+\Delta \varphi\right) \\
& \Delta P_{\text {tie12 }}=T_{12}\left(\Delta \delta_{1}-\Delta \delta_{2}\right)+T_{12} \Delta \varphi \\
& \text { Where } \Delta \delta_{1}=\int \Delta \omega_{1} d t \text { and } \Delta \delta_{2}=\int \Delta \omega_{2} d t
\end{aligned}
$$

From (12) and (13), we get,

$$
\Delta P_{t i e 12}=T_{12}\left(\int \Delta \omega_{1} d t-\int \Delta \omega_{2} d t\right)+T_{12} \Delta \varphi
$$

Laplace transformation of (14) yields

$$
\Delta P_{\text {tiel2 } 2}(s)=\frac{T_{12}}{s}\left[\Delta \omega_{1}(s)-\Delta \omega_{2}(s)\right]+T_{12} \Delta \varphi(s)
$$

From (15), the power flow over the tie-lines can be managed by regulating the phase shifter angle $\Delta \varphi(s)$ and as follows:

$$
\Delta \varphi(s)=\frac{K_{\varphi}}{1+s T_{P S}} \Delta \operatorname{Error}(s)
$$

Thus, (15) is as follows:

$$
\Delta P_{\text {tiel2 } 2}(s)=\frac{T_{12}}{s}\left[\Delta \omega_{1}(s)-\Delta \omega_{2}(s)\right]+T_{12} \frac{K_{\varphi}}{1+s T_{P S}} \Delta \operatorname{Error}(s)
$$

The deviation of speed $\left(\Delta \omega_{1}\right)$ is known and hence used as input signal to the TCPS to regulate the phase angle and hence regulate the power flow over the tie-lines. Hence,

$\Delta \varphi(s)=\frac{K_{\varphi}}{1+s T_{P S}} \Delta \omega_{1}(s)$

Finally, the power flow through tie-line perturbation becomes

$$
\begin{aligned}
& \Delta P_{\text {tiel2 }}(s)=\frac{T_{12}}{s}\left[\Delta \omega_{1}(s)-\Delta \omega_{2}(s)\right]+T_{12} \frac{K_{\varphi}}{1+s T_{P S}} \Delta \omega_{1}(s) \\
& \Delta P_{\text {tiel2 }}(s)=\Delta P_{\text {tiel2 }}^{o}+\Delta P_{T C P S}(s) \\
& \qquad \Delta P_{T C P S}(s)=T_{12} \frac{K_{\varphi}}{1+s T_{P S}} \Delta \omega_{1}(s) \\
& \text { where }
\end{aligned}
$$




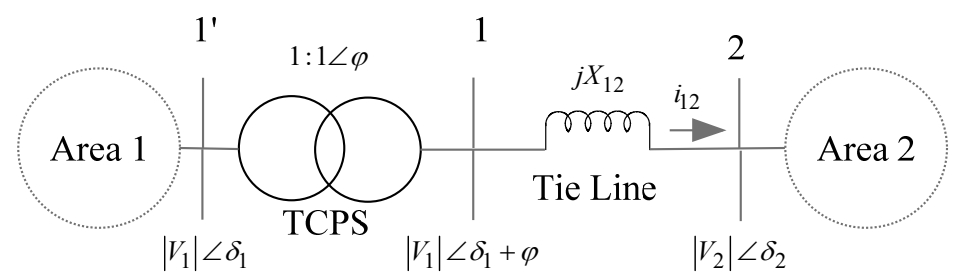

Figure 2. The considered system model with TCPS in series with the tie-line.

The TCPS as frequency regulator is shown in Figure 3

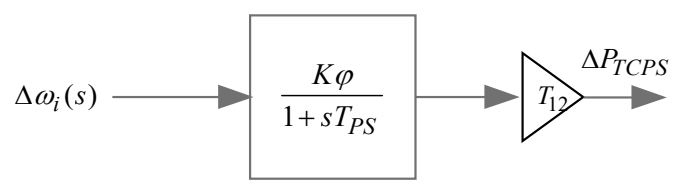

Figure 3. TCPS model

\subsection{Model of SMES for AGC}

The scheme in Figure 4 shows the thyristorcontrolled SMES unit configuration [10-11]. The SMES unit consists of a superconducting DC coil and converter connected with a $\mathrm{Y}-\Delta / \mathrm{Y}-\mathrm{Y}$ transformer to the grid. The dc voltage $(\mathrm{Ed})$ continually changes over the inductor within a given range of positive and negative values by controlling the firing angle of the converter. When the current reaches its rated value, the voltage across the inductor is kept constantly at zero, as the coil is superconductive. Ignore the converter and transformer losses and hence the DC voltage is given as follows [10]:

$$
E_{d}=2 V_{d o} \cos \alpha-2 I_{d} R_{c}
$$

Where Ed is the inductor voltage

$(\mathrm{kV})$, Id is the current that flows through the inductor $(\mathrm{kA}), \alpha$ is the firig angle

(o), Vdo is the maximum circuit voltage $(\mathrm{kV})$ and $\mathrm{Rc}$ is the proportional commuting resistance $(\Omega)$.

If $\alpha$ is under $90^{\prime}$, converter acts in loading mode, and if $\alpha$ is above $90^{\prime}$, converter acts in unloading mode.

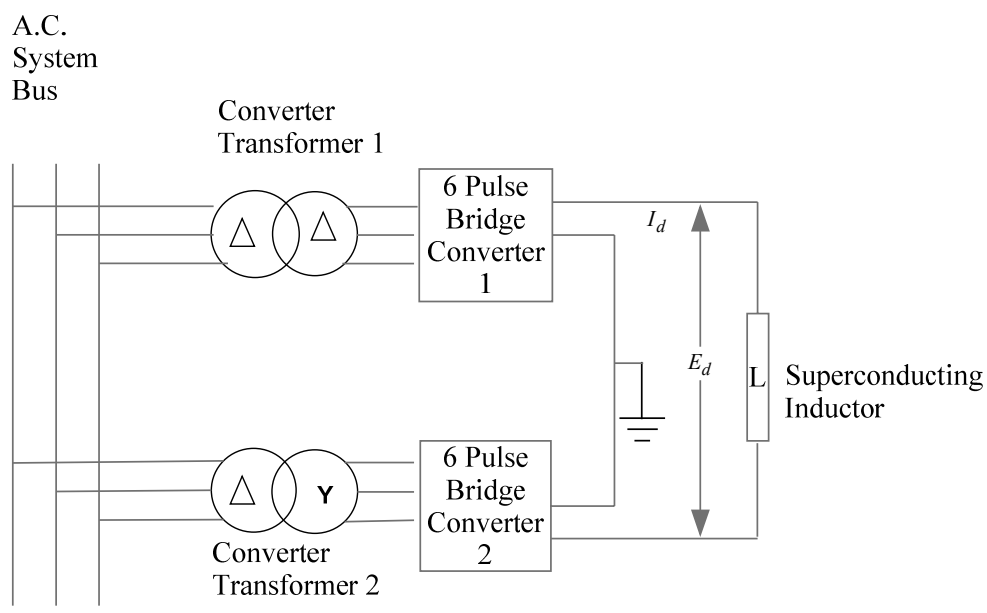

Figure 4. Schematic diagram of SMES unit 
When the dc voltage Ed is operated by the AGC, it is constantly regulated throughout the superconducting inductor depending on the error signal. Every SMES action is based on the error of the same area in the power system. In SMES control circuit, the induction current deviation is used as a negative feedback signal. This feedback signal provides a rapid current recovery due to the sudden changes in the power demand. After a system load disturbance, the inductor current must be rapidly restored to its nominal value in order to prepare for the next load disturbance. As a consequence, you can write the equations of inductor voltage and current deviation in Laplace form for each area as [10]:

$$
\begin{aligned}
& \Delta E_{d i}(s)=K_{0 i} \frac{1}{1+s T_{d c i}}\left[B_{i} \Delta f_{i}(s)+\Delta P_{i}(s)\right]-K_{I d i} \frac{1}{1+s T_{d c i}} \Delta I_{d i}(s) \\
& \Delta I_{d i}(s)=\frac{1}{s L_{i}} \Delta E_{d i}(s)
\end{aligned}
$$

Where KIdi is the feedback gain $\Delta \mathrm{Idi}$, the $\mathrm{K} 0 \mathrm{i}(\mathrm{kV} / \mathrm{ACE}$ unit) is a constant gain, the $\mathrm{Li}(\mathrm{H})$ is the coil inductance, and Tdci is a time delay of the converter. The variation in real inductor power is as follows in time domain:

$$
\Delta P_{s m i}(t)=\Delta E_{d i} I_{d i 0}+\Delta I_{d i} \Delta E_{d i}
$$

The energy saved in SMES at any moment in the time domain is;

$$
W_{s m i}(t)=\frac{L_{i} I_{d i}^{2}}{2}
$$

Finally, the Figure 5 shows the resulting SMES unit transfer function model.

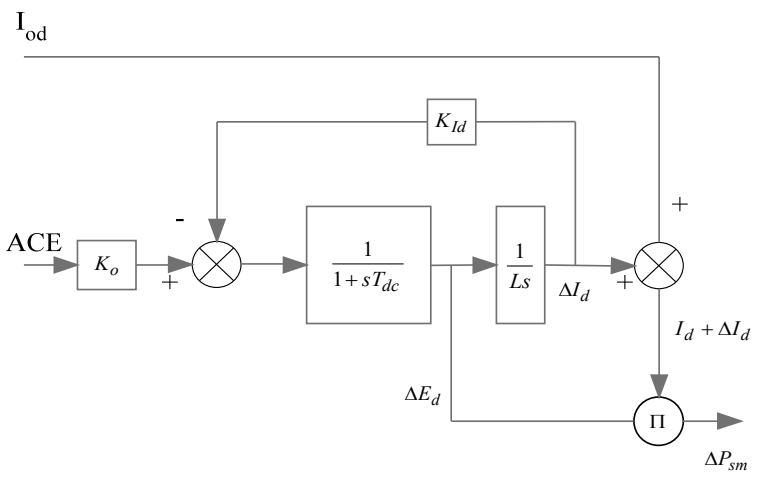

Figure 5. Block diagram of SMES unit

\subsection{Model of CES for AGC}

The basic setup of a CES unit in the power system is presented in Figure 6 [13-14]. A Power Conversion System (PCS), including a rectifier / inverter system attached to the network of the capacitor. The capacitor can be made up of many symmetric capacitors that are arranged in parallel and have an equivalent capacitance $\mathrm{C}$ as shown in Figure 6. Resistance $\mathrm{R}$ which is attached parallel to storage capacitor $\mathrm{C}$ represent its overall resistance considering leakage and dielectric losses of capacitor bank. The capacitor can be charged from the grid to a defined value (less than the total load) during normal grid operation. A gate turn-off thyristor (GTO) with reversing switch is used to alter the current direction in capacitor while charging \& discharging operation as the current direction can not change through bridge converters. When the demand for load suddenly increases, the stored energy is rapidly transferred to the grid via the PCS. As the governor and other control mechanisms begin to operate to set the system to a new balance, the capacitor quickly charges to its

Application of diverse FACTS in AGC of multi-area interconnected energy systems (Gulshan Sharma) 
initial value i.e. voltage. Similar action is for sudden decrease in the system load. The capacitor is charged quickly to its full value, thus absorbing excess energy from the system and as soon as the system returns to its stable state, the absorbed excess energy is released, and the capacitor voltage reaches to its normal value.

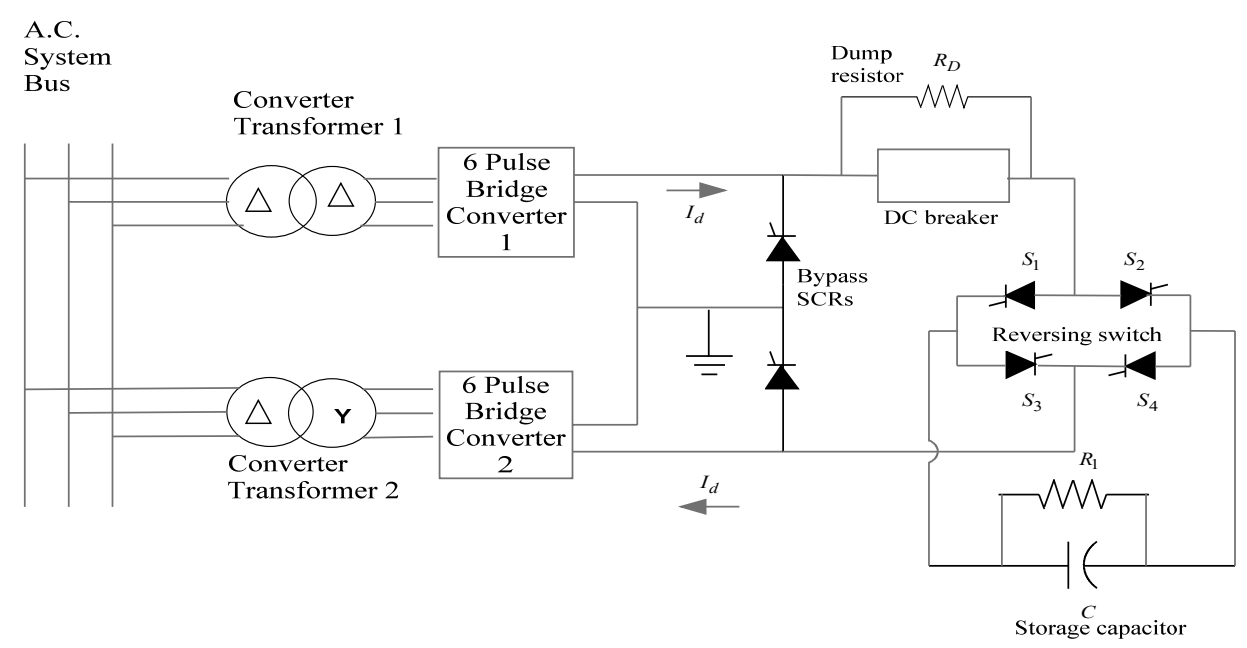

Figure 6. Schematic diagram of CES unit

Assuming the losses to be negligible, the bridge voltage Ed can be written as [14].

$$
E_{d}=2 E_{d o} \cos \alpha-2 I_{d} R_{D}
$$

By altering the $\alpha$ (phase angle) from 0 to $180^{\circ}$ the Ed can vary from its highest positive to its highest negative value. The capacitor works in such a way so that the maximum permissible energy absorption is equal to the maximum permissible energy output during normal operation and hence make the CES unit much effective to damp the system oscillations during sudden rise or decrease in the power demand and hence Edo indicates the set voltage value, Edmax and Edmin indicate the maximum and minimum voltage limit and can be written mathematically;

$$
\frac{1}{2} C E_{d \max }^{2}-\frac{1}{2} C E_{d o}{ }^{2}=\frac{1}{2} C E_{d o}{ }^{2}-\frac{1}{2} C E_{d \min }{ }^{2}
$$

and hence,

$$
\begin{aligned}
& E_{d o}=\left[\frac{E_{d \max }^{2}+E_{d \min }^{2}}{2}\right]^{\frac{1}{2}} \\
& \text { Let } E_{d \text { min }}=0.3 E_{d o} ; \text { Then } \\
& E_{d \max }=1.38 E_{d o}
\end{aligned}
$$

After a load disturbance, the value of the CES voltage must be returned to standard value as early as possible so that the CES unit will act on the next charging disturbance. Therefore, the capacitor voltage difference can be sensed and applied to the CES control loop as a negative feedback signal so the voltage can be restored quickly as shown in Figure 7. As the control signal to the CSE, the error of the power system is used. Hence, the deviation in current area for the ith area, $\Delta$ Idi is given as:

Indo. J. Elec. Eng. \& Inf, Vol.7, No. 2, June 2019: 241 - 254 


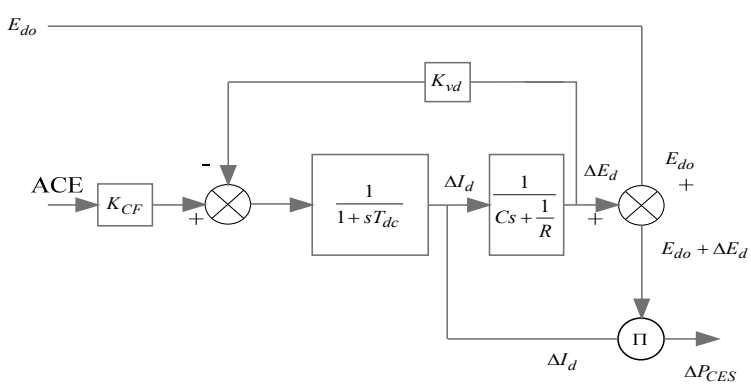

Figure 7. Block diagram of CES unit

$$
\Delta I_{d i}=\frac{\left[K_{A C E i} A C E_{i}-K_{v d} \Delta E_{d i}\right]}{1+s T_{D C i}}
$$

Where, $\mathrm{K}_{\mathrm{ACEi}}$ is the gain corresponding to $\mathrm{ACE}_{\mathrm{i}}$. In line with this control signals, Ed is continuously controlled. The deviation in capacitor voltage for the ith area is then determined as:

$$
\Delta E_{d i}=\left[\frac{R_{1}}{1+s C R_{1}}\right] \Delta I_{d i}
$$

When load disturbances occur, the capacitor power flow is given by:

$$
P_{d o}+\Delta P_{d}=\left(E_{d o}+\Delta E_{d}\right)\left(I_{d o}+\Delta I_{d}\right)
$$

The incremental capacitor power change is given by:

$$
\Delta P_{d}=\left(I_{d o} \Delta E_{d}+\Delta E_{d} \Delta I_{d}\right)
$$

The term $E_{d o} \Delta I_{d}$ is missing, since $E_{d o}=0$ the rated voltage is kept at constant value in storage mode. The increase in power flow per unit is then determined by:

$$
\Delta P_{d}=\left(I_{d o} \Delta E_{d}+\Delta E_{d} \Delta I_{d}\right) / P_{R}
$$

\subsection{Model of Governor Dead Band \& GRC}

A governor through deadband is defined as the overall quantity of the suistained speed changes where the position of the valve on the turbine does not change. The hysteresis type's non-linearity can be expressed as [13]:

$$
y=F(x, \dot{x})
$$

A basic premise needs to be made that variable $\mathrm{x}$ is close enough to a sinusoidal oscillation, i.e.

$$
x=A \sin \omega_{o} t
$$

Where $A$ is amplitude $\&$ frequency $\omega_{0}$ of the oscillations are fixed. Then

$$
\omega_{o}=2 \pi f_{o}=\pi, \text { with } f_{o}=0.5 H z
$$


The function $F(x, \dot{x})$ in Fourier series is as follows;

$$
\begin{aligned}
& F(x, \dot{x})=F^{o}+N_{1} x+\frac{N_{2}}{\omega_{o}} \dot{x}+--- \\
& F(x, \dot{x})=N_{1} x+\frac{N_{2}}{\omega_{o}} \dot{x} \\
& =\left(N_{1}+\frac{N_{2}}{\omega_{o}} \frac{d}{d t}\right) x=D B x
\end{aligned}
$$

For this work, a backlash of around $0.5 \%$ is selected and the Fourier results are $\mathrm{N} 1=0.8$ and N2=-0.2. Generation rate constraint (GRC): The generation can only be changed within the allowed range in a power system. [1-3]. The value of the GRC for thermal unit is $10 \% / \mathrm{min}(0.0017 \mathrm{pu} / \mathrm{s})$, i.e., GRC for the $i_{\text {th }}$ subsystem is:

$$
\left|\Delta P_{G i}(t)\right| \leq 0.0017 \text { p.u.MW/s }
$$

Within the AGC of the thermal system, two limits are limited to \pm 0.0017 to prevent excessive wear and tear of system equipments. Hence,

$$
\begin{aligned}
& \left|\Delta P_{G i}(t)\right| \leq 0.0017 \text { p.u.MW/s } \\
& \left|\Delta P_{G i}(t)\right| \leq 0.0017 \text { p.u. } M W / s \text {----------Lowering }
\end{aligned}
$$

The GRC for both control areas are considered by adding the limiters to the turbine.

\section{MODEL PREDICTIVE MODELLING}

In a number of control applications such as petroleum sector, electromechanical systems, and chemical processes, the MPC has been very efficient and effective for quick and effective control action. The design process is based on the explicit use of a forecast system response model to get control actions by reducing a defined target function. The objective for optimization includes minimizing the difference between the forecast and the reference response, and subject to the system constraints and the control action will be taken accordingly. The aim is mainly to compensate for unmet disturbances and model inexactitude by new measurements at each interval, as a consequence of which the system's output can differ from that predicted by the model [15-16]. The MPC controller model is illustrated in Figure 8. An internal model is used to forecast the plant's future outputs based on past and present inputs and output values and the proposed optimal control measures for the future. The total prediction can be calculated for a linear system in the MPC design by both summarizing free and forced answers. The optimiser is used to calculate the best possible set of future control actions after minimizing a costs function $(\mathrm{J})$, subject to manipulated and control variables system constraints.

The main goal is to minimize a future output error by a minimum input effort to zero. The reduced cost function is a weighted sum of predicted square errors and future control values.

$$
J\left(N_{1}, N_{2}, N_{u}\right)=\sum_{j=N_{1}}^{N_{2}} \beta(j)[\hat{y}(k+j \mid k)-w(k+j)]^{2}+\sum_{j=1}^{N_{u}} \lambda(j)[u(k+j-1)]^{2}
$$

Where N1 and N2 are the lower and upper horizons over the output, the control horizon is represented by $\mathrm{Nu}, \beta(\mathrm{j})$ and $\lambda(\mathrm{j})$ is weighting factors. In MPC design, the control horizon reduces the number of calculated future control according to the relation: $\Delta u(k+j)$ for $j \geq N_{u}$. The $w(k+j)$ is the reference trajectory over the future horizon $N$. The cost function can then be supplemented by restrictions over the control signal, the output and the control signal change [15]:

Indo. J. Elec. Eng. \& Inf, Vol.7, No. 2, June 2019: 241 - 254 


$$
\begin{aligned}
& u_{\min } \leq u(k) \leq u_{\max } \\
& \Delta u_{\min } \leq \Delta u(k) \leq \Delta u_{\max } \\
& y_{\min } \leq y(k) \leq y_{\max }
\end{aligned}
$$

The result of (40) provides the optimum monitoring signal sequence over Horizon N, which meets Equation's constraints as given in (41).

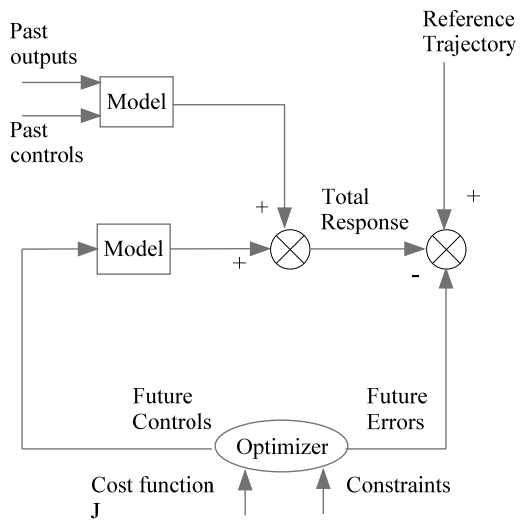

Figure 8. Structure of the MPC controller

\section{PRESENTATION OF RESULTS \& ITS ANALYSIS}

Firstly, the performace of AGC for thermal-thermal system considering the various combinations of FACTS i.e. TCPS - SMES, TCPS - CES, SMES - SMES and CES - CES using MPC technique for $1 \%$ load alteration is evaluated and presented. Figures $9-10$ shows the frequency alteration of area- 1 and alteration in tie-line power for $1 \%$ change in power demand.

The results clearly show the AGC enhancement with SMES in both thermal-thermal system with minimal overshoot and undershoot in frequency as well as in tie-line power. Furthermore, in comparison with the CES - CES, TCPS - SMES and TCPS - CES frequency stabilisers, the system frequency and tie-power fluctuations settle to zero steady state value within few seconds. It is also noted that TCPS - CES or TCPS SMES offer more settling time and larger overshoot in comparison to other frequency stabilizers under similar working conditions.

After above studies, the random load change is applied in control area-1 in order to evaluate the effectiveness of the various frequency stabilizers i.e. TCPS - SMES, TCPS - CES, SMES - SMES and CES CES using MPC. Figure $11-12$ shows the dynamic system responses for various system frequiency stabilizers. SMES - SMES coordinated operation is much superior to settle out the frequency oscillations to steady state value in thermal-thermal system and for tie-power in comparison to CES - CES, TCPS - CES and TCPS SMES oscillations.

The power of TCPS - SMES, TCPS - CES, SMES - SMES and CES - CES are also evaluated for sinusoidal load change and hence a sinusoidal load is applied in the area-1 in order to evaluate the efficiency of frequency stabilizers against the sinusoidal load pattern. The sinusoidal load change having low sub harmonics used to evaluate the performance of various frequency stabilizers are as follows:

$$
\Delta P_{L 1}=0.02 \sin (4.36 t)+0.05 \sin (5.3 t)-0.1 \sin (6 t)
$$

The system response following the application of the sinusoidal load change using the control action through MPC is shown in Figures 13 - 14. The operation with SMES-SMES works much more effectively and better than other frequencey stabilizers for damping oscillation in frequency and tie-line power response. It is also seen from the responses that oscillations are limited but do not damp to zero as change in sinusoidal load occur from 0 to 50 s on a continuous basis.

Application of diverse FACTS in AGC of multi-area interconnected energy systems (Gulshan Sharma) 
Finally, the performance of TCPS - SMES, TCPS - CES, SMES - SMES, and CES - CES using MPC for AGC are checked for GRC and governor deadband. The achieved results for $1 \%$ load change are shown in Figures 15 to 16 for TCPS-SMES, TCPS-CES, SMES-SMES, and CES-CES. It is found that system frequency oscillations as well as power exchange in tie-line with a CES or SMES placed in both areas with MPC provides minimum overshoot and undershoot. Also, the responses set to zero value in few seconds.

On the other hand, TCPS - SMES and TCPS - CES with MPC experience higher power output peaks with large steady state errors. In addition, it is also shown that the system with SMES in both areas with MPC offers the best dynamic system performance with respect to all aspects of AGC of energy delivery system. Power system data as shown in Table 1. SMES and CES data as shown in Table 2.

Table 1. Power System Data

\begin{tabular}{ccccc}
\hline Sr. No. & Area-1 & Area-2 & Description & Value \\
\hline 1 & Kp1 & Kp2 & Power system gain & $120 \mathrm{~Hz} /(\mathrm{p} . \mathrm{u} . \mathrm{MW})$ \\
2 & $\mathrm{~T} 12$ & - & Tie-line synchronizing coefficient & $0.545 \mathrm{p.u.} \mathrm{MW} / \mathrm{Hz}$ \\
3 & $\mathrm{Tg} 1$ & $\mathrm{Tg} 2$ & Governor time constant & $0.08 \mathrm{sec}$ \\
4 & $\mathrm{Tt1}$ & $\mathrm{Tt2}$ & Turbine time constant & $0.3 \mathrm{sec}$ \\
5 & $\mathrm{Tp} 1$ & $\mathrm{Tp} 2$ & Power system time constant & $20 \mathrm{sec}$ \\
6 & $\mathrm{R} 1$ & $\mathrm{R} 2$ & Regulation droop & $2.4 \mathrm{~Hz} /(\mathrm{p} . \mathrm{MW} . \mathrm{MW})$ \\
7 & $\mathrm{~B} 1$ & $\mathrm{~B} 2$ & Biasing coefficient & $0.425 \mathrm{p} . \mathrm{u} . \mathrm{MW} / \mathrm{Hz}$ \\
\hline
\end{tabular}

Table 2. SMES \& CES Data

\begin{tabular}{cccc}
\hline Sr. No. & & Description & Value \\
\hline 1 & L & Inductance of coil & $2.65 \mathrm{H}$ \\
2 & TDC & Converter time delay & $0.03 \mathrm{sec}$ \\
3 & KSMES & Gain of control loop & $100 \mathrm{KV} / \mathrm{unit} \mathrm{MW}$ \\
4 & Kid & Gain for feedback & $0.2 \mathrm{KV} / \mathrm{KA}$ \\
5 & $\mathrm{C}$ & Capacitance & $1 \mathrm{~F}$ \\
6 & $\mathrm{R}$ & Resistance & $100 \Omega$ \\
7 & TDC & Converter time delay & $0.05 \mathrm{~s}$ \\
8 & Kvd & Gain for feedback & $0.1 \mathrm{KA} / \mathrm{KV}$ \\
9 & KCES & Gain of control loop & $70 \mathrm{KA} /$ unit MW \\
\hline
\end{tabular}

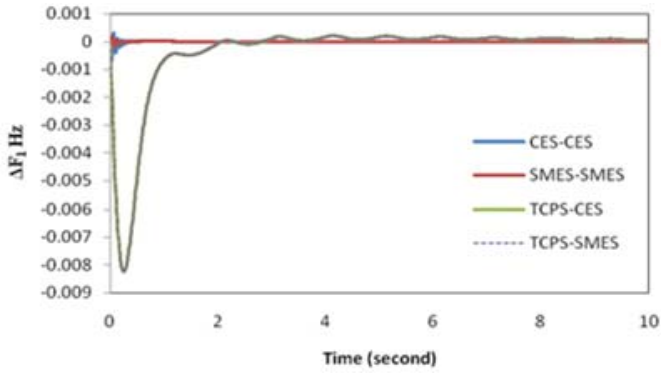

Figure 9. Response of $\Delta F_{1}$

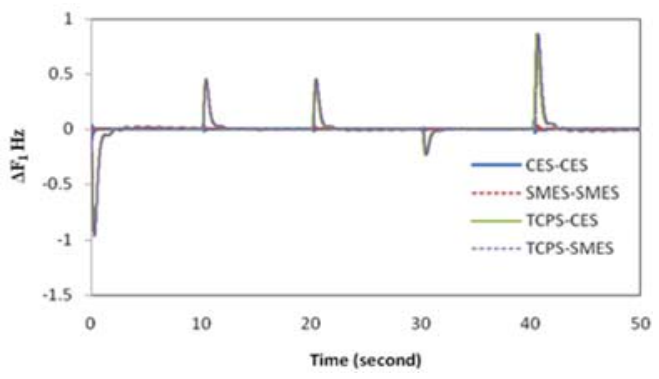

Figure 11. Response of $\Delta F_{1}$

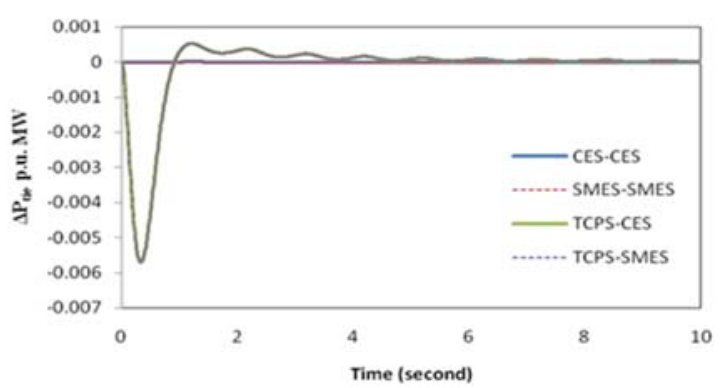

Figure 10. Response of $\Delta P_{\text {tie }}$

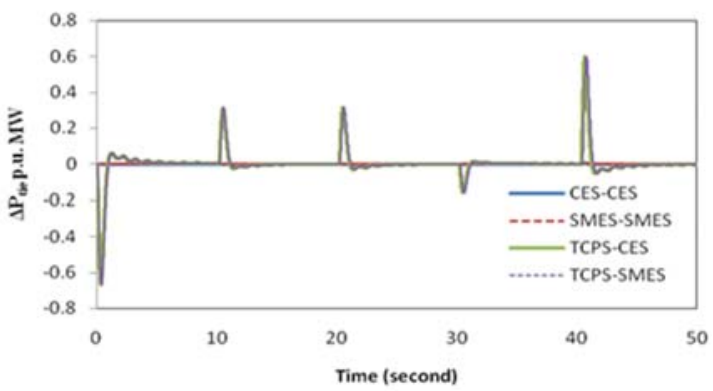

Figure 12. Response of $\Delta P_{\text {tie }}$ 


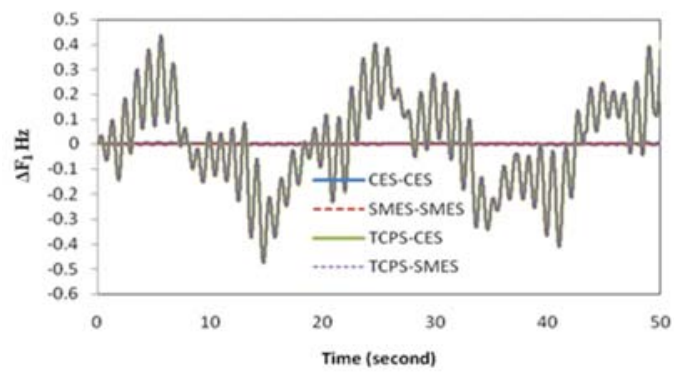

Figure 13. Response of $\Delta F_{1}$

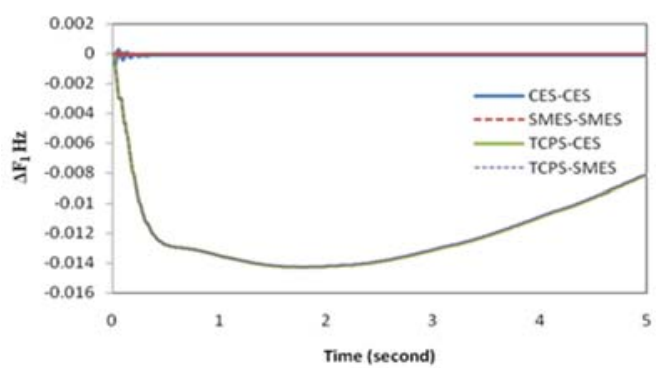

Figure 15. Response of $\Delta F_{1}$

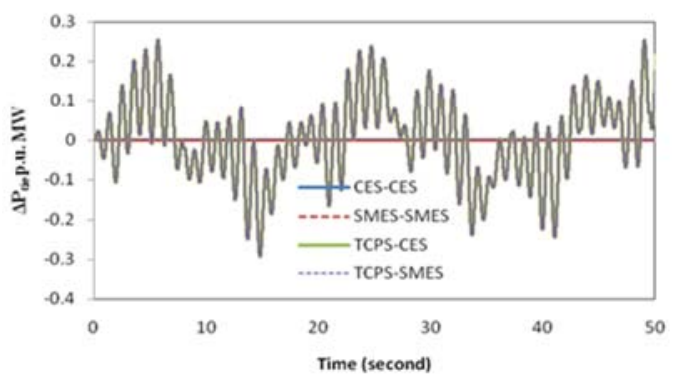

Figure 14. Response of $\Delta P_{\text {tie }}$

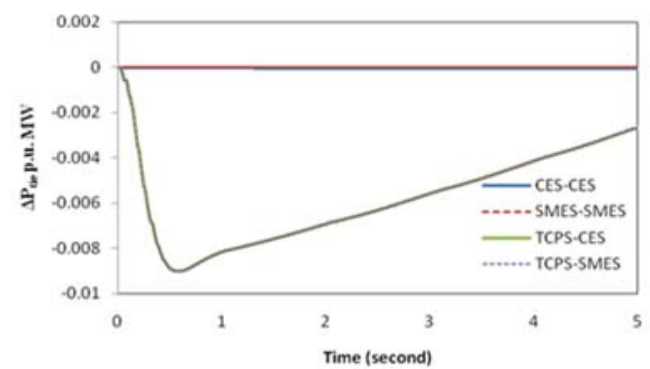

Figure 16. Response of $\Delta P_{\text {tie }}$

\section{CONCLUSIONS}

The current research work discusses the design of various frequency stabilizers for frequency control of interconnected thermal thermal energy delivery system using MPC technique. Coordinate functioning of SMES-SMES via MPC is actually effective for AGC system responses from a stable, as well as acceptable $1 \%$ load change, varying load pattern, sinusoidal load change and in the presence of the system non-linearities. The SMES located in the two control regions offers less undershoot and overshoot in frequency and tie-line power deviations than the CES - CES, TCPS - SMES and TCPS - CES using MPC for diverse test cases. Furthermore, it is also observed that the TCPS-CES or TCPS-SMES are more or less providing the same dynamic performance with large overshoot and more settling time as compared to that obtained with other frequency stabilizers in all test cases. In comparison to CES - CES or SMES - SMES, the coordinated operation of TCPS - CES or TCPS - SMES is much cheaper but the achieved performance is not within the acceptable limits and hence it can be concluded that SMES-SMES stabilizers offer promising performance for diverse test cases for AGC.

\section{REFERENCES}

[1] Gulshan Sharma, Ibraheem Nasiruddin, K. R. Niazi and R. C. Bansal, "Robust automatic generation control regulators for a two-area power system interconnected via AC/DC tie-lines considering new structures of matrix Q", IETGeneration Transmission and Distribution, vol. 10, no. 14, pp. 3570-3579, 2016.

[2] Sudha, K. R., and Santhi, R. V., "Robust decentralized load frequency control of interconnected power system with generation rate constraints using type-2 fuzzy approach," Elect. Power Energy syst., vol. 33, pp. 699-707, 2011.

[3] Parmar, K. P. Singh, Majhi, S., Kothari, D. P., "Load frequency control of a realistic power system with multi-source power generation," Elect. Power Energy syst., vol. 42, pp. 426-433, 2012.

[4] Gulshan Sharma, Ibraheem Nasiruddin, K. R. Niazi and R. C. Bansal, "Adaptive fuzzy critic based control design for AGC of power system connected via AC/DC tie-lines", IET-Generation Transmission and Distribution, vol. 11, no. 2, pp. 560-569, 2017.

[5] Ibraheem, Niazi, K. R., and Sharma, G., "Study on dynamic participation of wind turbines in AGC of power system," Electric Power Component and Syst., vol. 43, No. 1, pp. 44-55, 2014

[6] Sharma, G., Ibraheem, and Niazi, K. R., "Optimal AGC of asynchronous power systems using output feedback control strategy with dynamic participation of wind turbines," Electric Power Component and Syst., vol. 43, no. 4, pp. 384-398, 2015.

Application of diverse FACTS in AGC of multi-area interconnected energy systems (Gulshan Sharma) 
[7] Sharma, G., Niazi, K. R., Ibraheem, and Bansal, R. C., "LS-SVM based AGC of power system with dynamic participation from DFIG based wind turbines", 3rd Renewable Power Generation Conference (RPG), Naples, Italy, pp. $24-25,2014$.

[8] Ibraheem, Kumar, P., Kothari, D. P., "Recent philosophies of automatic generation control strategies in power systems," IEEE Trans. Power Syst., vol. 20, no. 1, pp. 346-57, 2005.

[9] Kunish, H. J., Kramer, K. G., and Domnik, H., "Battery energy storage-another option for load frequency control and instantaneous reserve," IEEE Trans. Energy Conv., vol. 1, no. 1, pp. 46-51, 1986.

[10] Demiroren, A., and Yesil, E., "Automatic generation control with fuzzy logic controllers in the power system including SMES units," Elect. Power Energy syst., vol. 26, pp. 291-305, 2004.

[11] Bhatt, P., Roy, R., and Ghoshal, S. P., "Coordinated control of TCPS and SMES for frequency regulation of interconnected restructured power systems with dynamic participation from DFIG based wind farm," Renew. Energy, vol. 40, pp. 40-50, 2012.

[12] Ghoshal, S. P., and Roy, R., "Evolutionary computation cased comparative study of TCPS and CES control applied to automatic generation control. In: Power system technology and IEEE power India conference, POWERCON; pp. $12-5,2008$.

13] Tripathy, S. C., Balasubramanian, R., Chandramohanan, Nair, P. S., "Small rating capacitive energy storage for dynamic performance improvement of automatic generation control," IEE PROCEEDINGS-C, vol. 138, no. 1, pp. 103-111, 1991.

[14] Abraham, R. J., Das, D., and Patra, A., "Effect of capacitive energy storage on automatic generation control. In: Power engineering conference, IPEC, pp. 1070-1074, vol. 2, 2005.

[15] Mohamed, T. H., Bevrani, H., Hassan, A. A., and Hiyama, T., "Decentralized model predictive based load frequency control in an interconnected power system," Energy Conv. and Manag., vol. 52, pp.1208-1214, 2011.

[16] Richalet, J., Rault, A., Testud, J.L., Japon, J., "Model predictive heuristic control. A application to industrial processes," Automatica, vol. 14, no. 5, pp. 413-28, 1978.

\section{BIOGRAPHY OF AUTHORS}

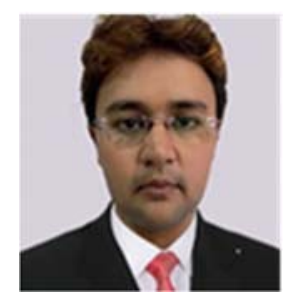

Dr. Gulshan Sharma is presently working as Senior Lecturer in Department of Electrical Power Engineering, Durban University of Technology, Durban, South Africa. He has more than 9 years of teaching and research experience. He has the qualifications of B. Tech, M. Tech and Ph.D. from Punjab Technical University (Punjab), Jamia Millia Islamia University (New Delhi) and Malaviya National Institute of Technology (Jaipur), India. He was a Post Doctoral research fellow at Faculty of EBIT, University of Pretoria, South Africa from 2015 to 2016. He has published a number of research papers in international journals and conferences of high repute and has been continuously engaged in guiding research activities at graduate/post-graduate and Ph.D. levels. His area of interest includes power system operation and control, renewable power generation, FACTS and application of AI techniques to power systems.

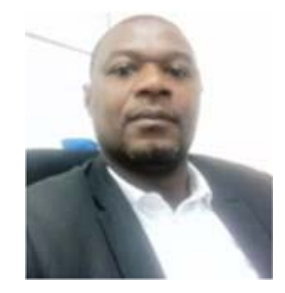

Kabulo Loji is since 2006 a Lecturer in the Department of Electrical Power Engineering at the Durban University of Technology in South Africa, after he has been in the industry since 1998 where he gained considerable field and design engineering experience. In 2004, hereceived his BTech Degree in Electrical Engineering at the Vaal University of Technology in South Africa and he is currently pursuing his M.Sc. qualification in Electrical Engineering at the University of KwaZulu-Natal in South Africa. His research interests lie in the areas of analysis, operation and control of power systens with emphasis on renewable energy sources penetration, andthe area of Engineering Education with special focus on Teaching for Learning in the engineering field.

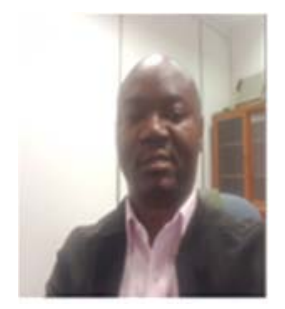

Dr. Kabeya Musasa received his BSc-Eng. in electromechanical engineering from University of Lubumbashi, Democratic Republic of Congo (DRC), in 2006, and his M.Tech. and M.Sc. in electrical power engineering from Tshwane University of Technology and the French graduate school (ESIEE Amiens), respectively, in 2012. He completed his PhD-Eng. at University of Pretoria, South Africa, in 2016. From January 2017 to July 2018, he was a postdoctoral researcher at University of Johannesburg, in South Africa. He is currently a senior lecturer in the Department of Electrical Power Engineering at Durban University of Technology. His research interests are in power electronics, including applications in renewable energy, smart grid, power system and electric drives. 